\title{
Postnatal 38. Günde Oral Parasetamol Tedavisiyle Kapanan Hemodinamik Anlamlı Patent Duktus Arteriosus Olgusu
}

\author{
A Hemodynamically Significant Patent Ductus Arteriosus Case which was Closed at 38th Day \\ with Oral Paracetamol Therapy
}

\author{
Selahattin AKAR ${ }^{1}$, Veysi ALMAZ ${ }^{1}$, Mehmet TURGUT ${ }^{2}$
}

1. Adlyaman Üniversitesi Ĕ̆itim ve Araştırma Hastanesi Yenidoğan Yoğun Bakım Ünitesi, Adıyaman, Türkiye

2. Özel Gözde Hastanesi, Çocuk Sağlığı ve Hastalıkları, Adıyaman, Türkiye

3. Adıyaman Üniversitesi, Ĕ̆gitim ve Araștırma Hastanesi, Çocuk Să̆lı̆̆lve Hastalıkları, Adıyaman, Türkiye

\section{$\ddot{O Z Z T}$}

Patent duktus arteriosus özellikle küçük prematürelerin önemli sorunlarından biridir. 25 gebelik haftasinda $515 \mathrm{gr}$ ă̆ırlığında doğan prematüre bebek yenidoğan servisine yatırildl. Respiratuvar distres sendromu (RDS) nedeniyle iki kez surfaktan tedavisi uygulanan hastanin postnatal 25. günde hemodinamik anlaml patent duktus arteriosus (PDA) saptanmasi nedeniyle hastaya 2 kür oral ibuprofen tedavisi verildi. İbuprofen sonrast duktusu kapanan hastanin postnatal 38. günde klinik ve laboratuvar olarak sepsis gelişen hastanın ekokardiyografisinde (EKO) duktusunun açıldiğ ve hemodinamik anlaml olduğu saptandl. Trombositopenisi olmast nedeniyle hastaya medikal kapatma tedavisi olarak oral parasetamol bașland. Oral parasetamol tedavisi sonrasi kontrol EKO'sunda PDA'nin

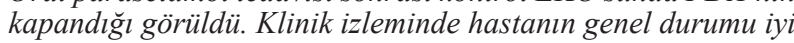
seyretti. Postnatal 110. günde 2120 grama ulaşan hasta yenidoğan polikliniğine kontrole gelmek üzere taburcu edildi. Sonuç olarak ibuprofen tedavisine yanit vermeyen ya da ibuprofen tedavisinin kontrendike olduğu durumlarda geç dönemde de parasetamol tedavisi alternatif seçenek olabilir.

Anahtar Kelimeler: prematüre,oral parasetamol,patent duktus arteriosus

\section{ABSTRACT}

Patent ductus arteriosus is one of the important problem in premature infants. A premature infant weighed $515 \mathrm{~g}$ at 25 th week of gestation was admitted in the neonatal intensive care unit. The patient administered surfactant therapy two times for respiratory distress syndrome (RDS) was given 2 cure of oral ibuprofen therapy due to hemodynamically significant patent ductus arteriosus (PDA) detected. Echocardiography of the patient whom ductus was closed after ibuprofen therapy and who clinically and laboratorially developed sepsis at the 38th postnatal day revealed that the ductus was hemodynamically significantly open. Upon the patient had thrombocytopenia, oral paracetamol therapy was initiated as medical closure treatment. After the treatment, control ECHO showed a closed PDA. General status of the patient was normal during the follow-up. The patient reached to 2,120 $\mathrm{g}$ at the 110 th postnatal day, and was discharged to home with outpatient clinic control plan. In conclusion, paracetamol treatment may be an alternative option also in late periods in the cases of unresponsiveness to ibuprofen or a contraindication for this agent.

Keywords: premature,oral paracetamol,patent duktus arteriosus

\section{İletişim}

Sorumlu Yazar: Selahattin AKAR

Adres: Adıyaman Üniversitesi Eğitim ve Araştırma Hastanesi Yenidoğan Yoğun Bakım Ünitesi, Adıyaman, Türkiye

Tel: +90 (506) 3672453

E-Posta: selahattinakar2001@yahoo.com

Makale Geliş: 25.07.2018

Makale Kabul: 24.04.2019

DOI: http://dx.doi.org/10.16948/zktipb.447404

\section{GİRIŞ}

Miadında doğan bebeklerin çoğunda duktus arteriozus hayatın ilk 3-4 gününde spontan olarak kapanır. Prematüre bebeklerde ise gebelik haftasına bağlı olmakta beraber kapanma gerçekleşmeyebilir (1). Hemodinamik anlamlı PDA'ya bağlı soldan sağa şantın kalp, akciğer, gasrointestinal sistem ve böbrekler üzerindeki yan etkiler bilindiğinden, bu sistemler üzerindeki etkiler çıkmadan PDA'nın erken dönemde kapatılması gerektiğini bildiren çalışmalar vardır $(1,2)$.

PDA medikal veya cerrahi olarak kapatılabilmektedir. PDA'nın medikal kapatılmasında en s1k indometazin ve ibuprofen kullanılmaktadır. Her iki ilacın PDA kapatmada etkinliği aynıdır ve \%70-80 başarı oranı sağlar. Her iki ilacın da gastrointestinal sistem ve renal sistem üzerinde yan etkileri olabilmektedir (3-6). İntravenöz ibuprofen pahalı olması ve çoğu yerde bulunamaması nedeniyle oral ibuprofen tercih edilmektedir $(7,8)$. Son y1llarda intravenöz veya oral parasetamolun de PDA'nın medikal kapatma tedavisinde etkin olduğunu bildiren çalışmalar bildirilmiştir (9-11).

$\mathrm{Bu}$ yazıda prematüre bebekte hemodinamik anlaml PDA saptanan ve ibuprofen tedavisinin kontrendike olması nedeniyle geç dönemde parasetamol tedavisine yanit veren olgu sunuldu.

\section{OLGU}

25 gebelik haftasında 515 gr ağırlığında sezeryan ile doğan ve postnatal solunum sıkıntısı görülen erkek hasta yenidoğan yoğun bakım ünitemize interne edildi. Solunumu dispneik,takipnek ve belirgin interkosal çekilmeleri olan hasta entübe edilerek mekanik ventilator desteği sağlandı. Klinik ve radyolojik olarak respiratuar distres sendromu düşünülen hastaya $2 \mathrm{kez}$ surfaktan tedavisi uygulandi. Yenidoğan servisine yatışında kardiyovasküler sistem ve batın muayenesi normal olarak değerlendirildi. Steril şartlarda umblikal venöz ve arter kateteri takıld1. Minimal enteral beslenme başlanan hastaya umblikal venden ilk gün TPN desteği başlandı. Enteral alımı kademeli olarak artırıldı. Kranial ultrasonografisinde kanama saptanmadi. Postnatal 3., 5., 9. günlerde ekokardiyografisinde patoloji saptanmadi. Entübe olarak izlenen hastaya postnatal 10. ve 15 . günlerde ekstübasyon denendi ancak k1sa sürede desatüre olması, subkostal ve interkostal çekilmele- 
rinin olması nedeniyle reentübe oldu. Postnatal 18 . günde bronkopulmoner displazi kliniği düşünülerek 3 günlük steroid tedavisi başlandı. Postnatal 25. günde 2/6 üfürümü saptanan hastanın ekokardiyografisinde hemodinamik anlamlı PDA (duktus çap1 $>1,5$ $\mathrm{mm}$ ve sol atrium/aorta oranı $>1,5)$ saptanmas1 üzerine hastaya 1 . gün $10 \mathrm{mg} / \mathrm{kg}, 2$. gün $5 \mathrm{mg} / \mathrm{kg}, 3$. gün $5 \mathrm{mg} / \mathrm{kg}$ olacak şekilde oral ibuprofen tedavisi başland1. Oral ibuprofen sonrası ekokardiyografisinde PDA'nın hala açık ve geniş olması nedeniyle 2. kür oral ibuprofen tedavisi verildi. Hastanın 2. kür ibuprofen tedavisi sonrası PDA'sının kapandığ1 saptand1. İbuprofen tedavisi öncesi ve sonrası kan biyokimyası normal idi. Entübe olarak takip edilen hastada postnatal 38. günde klinik ve laboratuvar olarak sepsis gelişmesi nedeniyle hastaya vankomisin + meropenem antibiyotik tedavisi başland. Fizik muayenesinde 2/6 üfürümü saptanan hastanın ekokardiyografisinde hemodinamik anlamlı PDA saptand1 (Resim 1). Tetkiklerinde trombositopenisi $(<50$. 000) olmasi nedeniyle hastaya medikal kapatma tedavisi olarak oral parasetamol $60 \mathrm{mg} / \mathrm{kg} /$ gün 4 doz, 3 gün olarak başlandı. Oral parasetamol tedavisi sonrası kontrol EKO'sunda PDA'nın kapandığı görüldü. Parasetamol tedavisi süresince parasetamole bağlı herhangi bir yan etki saptanmadı. Klinik izleminde hastanın genel durumu iyi seyretti. Postnatal 110. günde 2120 grama ulaşan hasta yenidoğan polikliniğine kontrole gelmek üzere taburcu edildi.

\section{TARTIŞMA}

Duktus kapatılmasında en s1k nonselektif siklooksijenaz (COX 1) enzim inhibitörleri olan indometazin ve ibuprofen kullanılmaktadir. Ancak her iki ilacin da gastointestinal kanama, böbrek yetmezliği, intestinal perforasyon, trombosit agregasyonunu bozma,hiperbilirubinemi,periferik vazokonstruksiyon gibi yan etkileri görülebilmektedir (82-85). Öte yandan intraventriküler kanama (IVK), nekrotizan enterokolit (NEK),trombositopeni ve akut böbrek yetmezliği bu ilaçların kullanımı için kontrendikasyon oluşturur $(12,13)$.

Günümüzde PDA'nın medikal kapatılmasında ibuprofen tedavisine yanit vermeyen veya ibuprofen tedavisinin kontrendike olduğu durumlarda parasetamol tedavisi kulanilabilmektedir. Parasetamolun duktus kapanmasındaki rolü ilk kez Hammerman ve arkadaşları tarafından olgu serisi șeklinde bildirilmiștir. İbuprofen tedavisinin kontrendike olduğu veya ibuprofen tedavisine yanıt alınamayan gebelik haftası 26-32 olan 5 preterm bebeğe oral parasetamol tedavisi başlanmış ve tedavi sonrası tamamında duktusun kapandığı bildirilmiştir (11). Ülkemizden Memişoğlu ve arkadaşlarının bildirdiği çalışmada intravenöz parasetamol başlanan 11 olgunun 10'nunda $(\% 90,9)$ PDA'nın kapandığ1 bildirilmiştir (14). Yine ülkemizden Öncel ve arkadaşlarının bildirdiği çalışmada ibuprofene yanıt vermeyen ya da ibuprofen tedavisinin kontrendike olduğu olgularda kapanma oranı \%87,5 olarak bildirilmiştir (15).

İntrauterin dönemde duktal açıklığı sağlayan prostoglandinler;siklooksijenaz (COX) ve peroksidaz komponentlerinden oluşan Prostoglandin $\mathrm{H} 2$ Sentetaz (PGH2S) tarafindan sentezlenir (16). Parasetamolun peroksidaz komponentine etki ettiği bildirilmektedir $(17,18)$. Duktusun kapanmasinda trombositlerin rolü olduğu bilinmektedir. Parasetamolun anti-trombosit etkisi diğer nonsteroidler antiinflamatuar ilaçlardan daha az olduğundan duktus kapanmasında bu mekanizmayla da etki edebileceği düşünülmektedir (19-21).

Sepsis gelişen yenidoğanlarda dolaşımda artan prostoglandinler ve sitokinler nedeniyle kapalı PDA tekrar açılabilir ve tedaviye yanıt alınamayabilir (22). Olgumuzda postnatal 25. günde hemodinamik anlamlı PDA nedeniyle oral ibuprofen tedavisi başlanmış ve iki kür tedavi sonrası duktusun kapand1ğ1 saptanmışt1 ancak postnatal 38. günde klinik ve laboratuvar olarak sepsis tablosu geliştiğinden duktusta tekrar açılma saptandı. Trombositopenisi ne-

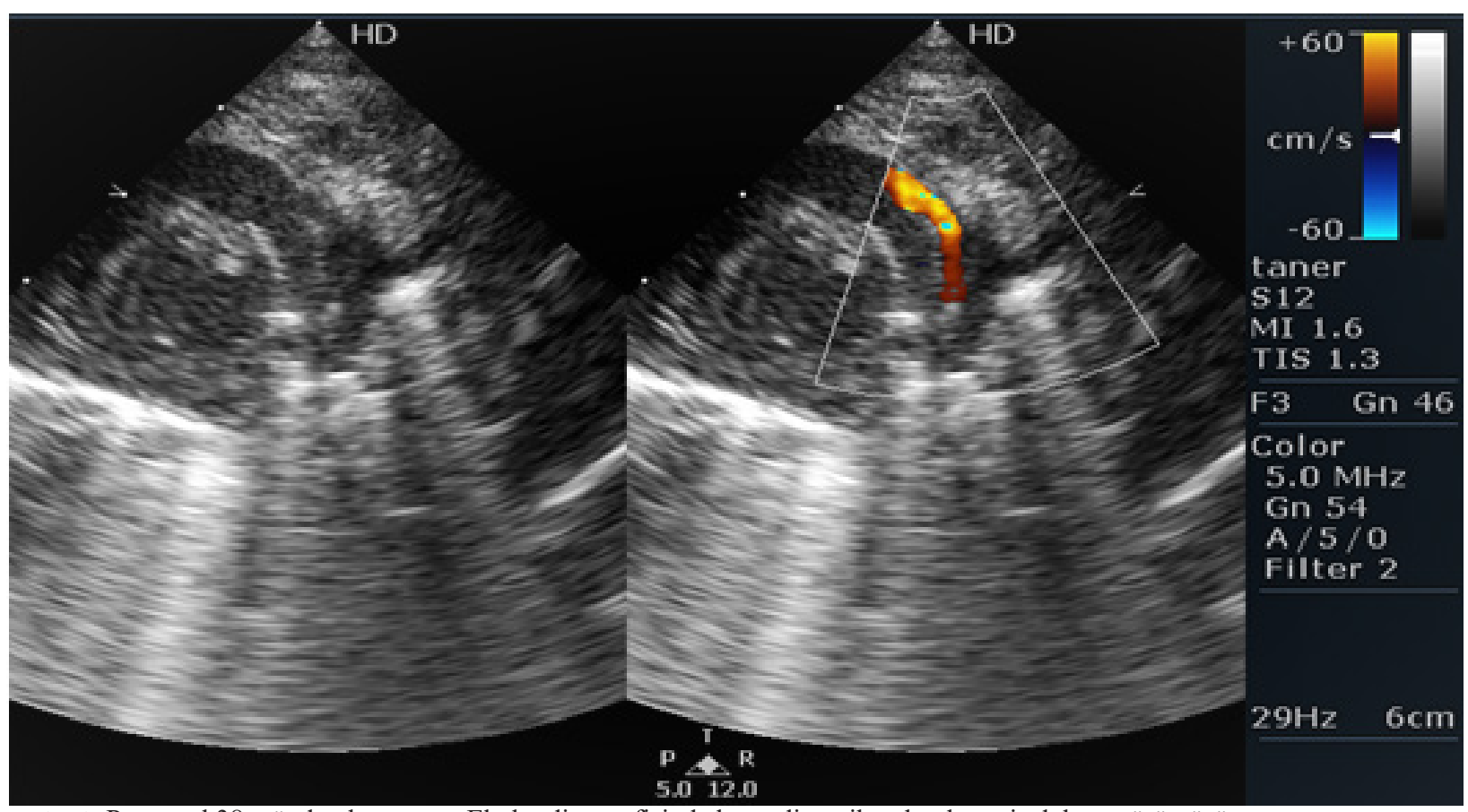

Resim 1: Postnatal 38. günde olgumuzun Ekokardiyografisinde hemodinamik anlamlı geniş duktus görüntüsü. 
deniyle ibuprofen tedavisi kontrendike olduğundan hastamıza oral parasetamol tedavisi, $60 \mathrm{mg} / \mathrm{kg} / \mathrm{gün}$ 4 doz,3 gün şeklinde başladık.

Bildirilen olgu serisi çalışmalarının bir kısmında oral parasetamol bir kısmında ise intravenöz parasetamol kullanılmıștır $(11,14,23,24)$. Bizim olgumuzda da kusma, gastrik rezidü artışı gibi beslenme intoleransı olmadığ 1 için oral parasetamol tedavisi başladık.

Tekgündüz KȘ ve arkadașlarının bildirdiği çalışmada intravenöz parasetamol tedavisi sonrası karaciğer enzimlerinde yükselme olduğunu ve bundan dolayı düşük doz parasetamol tedavisiyle devam ettiklerini bildirmişlerdir (25). Bizim olgumuzda tedavi süresince parasetamole bağlı herhangi bir hepatotoksisite bulgusu saptanmad1.

Roofthooft ve arkadaşları çalışmalarında ibuprofen tedavisine yanit vermeyen olgularda parasetamol tedavisinin etkili olmadığını bildirmişler. Yine aynı çalıșmada erken dönemde parasetamol tedavisinin etkili olabileceği ancak postnatal 2 haftadan sonra parasetamol tedavisinin etkili olmadığ1$\mathrm{n} 1$ bildirmişlerdir (26).

Sonuç olarak son yıllarda PDA kapatmasında parasetamolun popülerliği giderek artmaktadır. Her ne kadar günümüzde PDA'nın medikal kapatılmasında ilk seçenek olarak oturmamışsa da ibuprofene yanit vermeyen veya ibuprofen tedavisinin kontrendike olduğu olgularda alternatif seçenek olarak tercih edilebilir.

\section{KAYNAKLAR}

1. Gregoire N, Gualano V, Geneteau A, et al. Population pharmacokinetics of ibuprofen enantiomers in very premature neonates. J Clin Pharmacol 2004; 44:1114-1124.

2. Mahony L, Caldwell RL, Girod DA, et al.Indomethacin therapy on the first day of life in infants with very low birth weight. J Pediatr 1985;106:801-805.

3. Bagnoli F, Rossetti A, Messina G, Mori A, Casucci M, Tomasini B. Treatment of patent ductus arteriosus (PDA) using ibuprofen: renal side-effects in VLBW and ELBW newborns. $J$ Matern Fetal Neonatal Med. 2013;26(4):423-429.

4. Akima S, Kent A, Reynolds GJ, Gallagher M, Falk MC. Indomethacin and renal impairment in neonates. Pediatr Nephrol 2004;19(5):490-493.

5. Kanmaz G, Erdeve O, Canpolat FE, Oğuz SS, Uras N, Altug N, Greijdanus B, Dilmen U. Serum ibuprofen levels of extremely preterm infants treated prophylactically with oral ibuprofen to prevent patent ductus arteriosus. Eur J Clin Pharmacol 2013;69(5):1075-1081.

6. Fujii AM, Brown E, Mirochnick M, O'Brien S, Kaufman $G$. Neonatal necrotizing enterocolitis with intestinal perforation in extremely premature infants receiving early indomethacin treatment for patent ductus arteriosus. J Perinatol 2002;22(7):535540 .

7. Olukman O, Calkavur S, Ercan G, Atlihan F, Oner T, Tavli $V$, Kultursay N. Comparison of oral and intravenous Ibuprofen for medical closure of patent ductus arteriosus: which one is better? Congenit Heart Dis.2012;7(6):534-43.

8. Erdeve O, Yurttutan S, Altug N, Ozdemir R, Gokmen T, Dilmen U, Oguz SS, Uras N. Oral versus intravenous ibuprofen for patent ductus arteriosus closure: a randomised controlled trial in extremely low birthweight infants. Arch Dis Child Fetal Neonatal Ed 2012;97(4):F279-83.
9. Jasani B, Kabra N, Nanavati R. Oral paracetamol in treatment of closure of patent ductus arteriosus in preterm neonates. $J$ Postgrad Med 2013;59:312-14.

10. Sancak S, Gokmen Yildirim T, Topcuoglu S, Yavuz T, Karatekin $G$, Ovali $F$. Oral versus intravenous paracetamol: which is better in closure of patent ductus arteriosus in very low birth weight infants? J Matern Fetal Neonatal Med 2014;23:1-5.

11. Hammerman C, Bin-Nun A, Markovitch E, et al. Ductal closure with paracetamol: a surprising new approach to patent ductus arteriosus treatment. Pediatrics 2011;128:e1618-21.

12. Bagnoli F, Rossetti A, Messina G, Mori A, Casucci $M$, Tomasini B:Treatment of patent ductus arteriosus (PDA) using ibuprofen: renal side-effects in VLBW and ELBW newborns. $J$ Matern Fetal Neonatal Med 2013;26(4):423-429.

13. Erdeve O, Sarici SU, Sari E, Gok F:Oral-ibuprofen-induced acute renal failure in a preterm infant. Pediatr Nephrol 2008;23(9): 1565-1567.,

14. Memisoglu A, Alp Ünkar Z, Cetiner N, Akalın F, Ozdemir $H$, Bilgen HS, Ozek E.Ductal closure with intravenous paracetamol: a new approach to patent ductus arteriosus treatment. $J$ Matern Fetal Neonatal Med. 2016;29(6):987-990.

15. Oncel MY, Yurttutan S, Uras $N$, et al. An alternative drug (paracetamol) in ibuprofen resistant or contraindicated preterm infants.Arch Dis Child Fetal Neonatal Ed 2013;98:F94-5.

16. Clyman RI. Mechanisms regulating the ductus arteriosus. Biol Neonate 2006;89:330-5.

17. Dang D, Wang D, Zhang C, et al. Comparison of oral paracetamol versus ibuprofen in premature infants with patent ductus arteriosus:a randomized controlled trial. PLoS One 2013;8:e77888.

18. Oncel MY, Yurttutan S, Erdeve O, et al. Oral paracetamol versus oral ibuprofen in the management of patent ductus arteriosus in preterm infants. A randomized controlled trial. J Pediatr 2014;164:510-14.

19. Graham GG, Davies MJ, Day RO, Mohamudally A, Scott $K F:$ The modern pharmacology of paracetamol: therapeutic actions, mechanism of action, metabolism, toxicity and recent pharmacological findings.Inflammopharmacol 2013;21(3):201-232.

20. Echtler K, Stark K, Lorenz M, Kerstan S, Walch A, Jennen L, Rudelius M. Seidl S,Kremmer E, Emambokus NR, von Bruehl ML, Frampton J, Isermann B, Genzel Boroviczény O, Schreiber C, Mehilli J, Kastrati A, Schwaiger M,Shivdasani RA, Massberg S:Platelets contribute to postnatal occlusion of theductus arteriosus.Nat Med 2010;16(1):75-82.

21. Clyman $R$, Chemtob $S$ :Vessel remodeling in the newborn: platelets fill the gap.Nat Med 2010;16(1):33-35.

22. Gonzalez A, Sosenko IRS, Chandar J, et al. Influence of infection on patent ductus arteriosus and chronic lung disease in premature infants weighting 1000 grams or less. J Pediatr 1996; $128(4): 474-478$.

23. Yurttutan S, Oncel MY, Araylct S, et al. A different first-choice drug in the management of patent ductus arteriosus: oral paracetamol. J Matern Fetal Neonatal Med 2013;26:825-827.

24. Oncel MY, Yurttutan S, Degirmencioglu H, et al. Intravenous paracetamol treatment in the management of patent ductus arteriosus in extremely low birth weight infants. Neonatology 2013;103:166-169.

25. Tekgündüz KŞ, Ceviz N, Caner I, Olgun H, Demirelli Y, Yolcu C, Şahin IO, Kara M. Intravenous paracetamol with a lower dose is also effective for the treatment of patent ductus arteriosus in pre-term infants. Cardiol Young 2015;25(6):10601064.

26. Roofthooft DW, van Beynum IM, Helbing WA, Reiss IK, Simons SH: Paracetamol for ductus arteriosus closure: not always a success story.Neonatology 2013;104(3):170. 